\title{
Corrosion Inhibition of Low Carbon Steel in 1 M HCl Solution by Cephalexin Monohydrate Drug and Synergistic Iodide Addlitives
}

\author{
Samar. Y. Al-Nami ${ }^{1}$ \\ 1 Chemistry Department, Science College for Girls, King Khalid University, Abha, KSA \\ * Correspondence: salnamee@kku.edu.sa;
}

Received: 3.07.2020; Revised: 28.07.2020; Accepted: 29.07.2020; Published: 2.08.2020

\begin{abstract}
The effect of Cephalexin monohydrate drug on the corrosion performance of low carbon steel (LCS) in $1 \mathrm{M} \mathrm{HCl}$ solution has been examined by weight reduction (WR), potentiodynamic polarization (PP) and AC impedance spectroscopy (EIS) tests. The inhibition efficiency (IE) raised with increasing the cephalexin monohydrate drug dose but lowered with higher temperatures. The adsorption of the Cephalexin monohydrate drug established to follow Temkin isotherm. The PP tests designated that the cephalexin monohydrate drug is of mixed type. Synergism among iodide ion and cephalexin monohydrate drug was suggested. The outcome data gotten from the three altered tests were in excellent agreement. Theoretical relationships have been utilized to examine the influence of molecular structure on IE of the Cephalexin monohydrate drug.
\end{abstract}

Keywords: Corrosion inhibition; LCS; HCl; Cephalexin monohydrate drug; Synergistic effect.

(C) 2020 by the authors. This article is an open-access article distributed under the terms and conditions of the Creative Commons Attribution (CC BY) license (https://creativecommons.org/licenses/by/4.0/).

\section{Introduction}

Low carbon steel is a material frequently utilized because of its properties of protection to corrosion in both the maritime field and the industrial domain. LCS has been selected in this paper because of its frequently utilized, and 'it's weak relatively resistant to dissolution, allowing to assess more easily the effect of the environment. It is probable to decrease the rate of dissolution to a safe level by appending inhibitors. Several heterocyclic composites containing $\mathrm{N}, \mathrm{O}$, and $\mathrm{S}$ either in the aromatic or long carbon chain system have been described to be productive inhibitors [1-4]. These compounds have including functional groups (such as $-\mathrm{OR},-\mathrm{C}=\mathrm{C}-,-\mathrm{OH},-\mathrm{NR}_{2},-\mathrm{NH}_{2}$ and $\left.-\mathrm{SR}\right)$. These groups afford electrons that enable the inhibitor adsorbed of on the metal superficial [5-10]. Most of the organic inhibitors are cost, poisonous, and have a side influence on the atmosphere this property restricts ' it's utilized to protect the metal dissolution. Therefore, it is significant and essential to improving small price and eco-friendly corrosion protection $[11,13]$. As of late specialists have focused on the improvement of medications as drugs for metallic dissolution. In the review, numerous writers have described the impact of drugs on the corrosion of metals in a corrosive environment [1426]. The choice of this drug Cephalexin monohydrate as a corrosion inhibitor is based on the resulting:(a) can be simply obtained (b) including active atom such as (O, N and $\mathrm{S}$ ) (c) has solubility higher in a corrosive environment (d) non-hazardous and (e) low cost.

The current study aimed to utilized cephalexin monohydrate drug has studied the hindering effect on the dissolution of LCS in $1 \mathrm{M} \mathrm{HCl}$. Also, the association among deliberate quantum parameters and \%IE of the cephalexin monohydrate drug was debated. 


\section{Materials and Methods}

\subsection{Materials.}

The tests were achieved with LCS samples with the composition shown in Table 1.

\begin{tabular}{c|c|c|c|c|c|c|c|c}
\multicolumn{1}{l}{ Table 1. The LCS weight percentage. } \\
Elements & $\mathbf{C}$ & $\mathbf{C r}$ & $\mathbf{N i}$ & $\mathbf{S i}$ & $\mathbf{M n}$ & $\mathbf{P}$ & $\mathbf{S}$ & $\mathbf{F e}$ \\
\hline Wt $\%$ & 0.14 & 0.1 & 0.01 & 0.024 & 0.5 & 0.05 & 0.05 & Reset
\end{tabular}

All chemicals and reagents utilized are with investigative grade and utilized deprived of further purification (utilized as received).

\subsection{Materials and Solutions.}

The corrosive environment utilized was $37 \% \mathrm{HCl}$ (AR grade). "Appropriate doses of acid were ready utilized distilled water. $1000 \mathrm{ppm}$ stock solutions from the examined cephalexin monohydrate drug were ready by liquefying the suitable weight of the utilized chemically pure solid drug in second distilled water. The cephalexin monohydrate drug stock solution $10^{3} \mathrm{ppm}$ was used to prepare $(100,200,300,400,500$, and $600 \mathrm{ppm})$ ". The structure of the cephalexin monohydrate drug was utilized as a corrosion hindrance for LCS in $1 \mathrm{M} \mathrm{HCl}$.

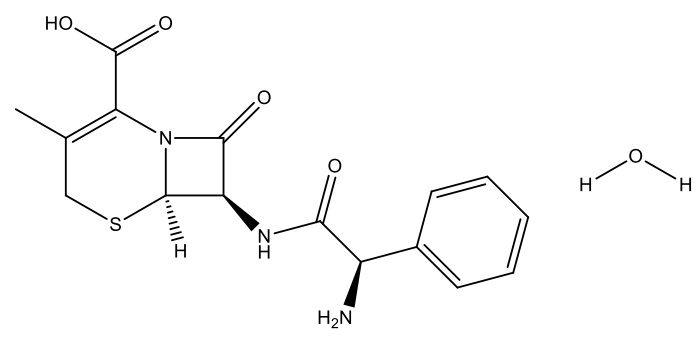

Scheme 1. Cephalexin monohydrate drug.

\subsection{Techniques used for corrosion measurements.}

\subsubsection{Weight loss method (WL).}

Three parallel LCS sheets of $2 \times 2 \times 0.2 \mathrm{~cm}$ were abraded with emery paper up to 1200 grit and then washed with bidistilled water and acetone. "Pre-treatment and pre-weighed carbon steel specimens were immersed in the aggressive media in the absence and presence of studied additives with the concentration range of $(100-600 \mathrm{ppm})$. The maximum duration of immersion was $180 \mathrm{~min}$. After equal time intervals $(30 \mathrm{~min}$ ), the specimens were taken out, rinsed with distilled water, air-dried, and accurately weighed. All the experiments were achieved in triplicate in order to ensure reproducibility. Then the tests were ready at altered temperatures. The (\%IE) and the grade of surface coating $(\theta)$ of cephalexin monohydrate drug on the dissolution of LCS were measured from the next balances" [27]:

$$
\begin{array}{r}
\mathrm{IE} \%=\left[\left(\mathrm{W}^{\circ}-\mathrm{W}\right) / \mathrm{W}^{\circ}\right] \times 100 \\
\theta=\left[\left(\mathrm{W}^{\circ}-\mathrm{W}\right) / \mathrm{W}^{\circ}\right]
\end{array}
$$

where $\mathrm{W}^{\circ}$ and $\mathrm{W}$ are the data of the WL attendance and lack of appending of the cephalexin monohydrate drug, correspondingly. 


\subsubsection{Electrochemical methods.}

\subsubsection{1. i-PP tests.}

Further corrosion tests were analyzed electrochemically in a three-compartment glass cell consisted of the working electrode "(LCS electrode) with an uncovered area of $1 \mathrm{~cm}^{2}$, the reference electrode (saturated calomel electrode) and the counter electrode (a platinum foil). Electrochemical tests were carried out under the static conditions in a naturally aerated solution of $1 \mathrm{M} \mathrm{HCl}$ in the attendance and lack of varied doses of additives (cephalexin monohydrate drug) at $25 \pm 1{ }^{0} \mathrm{C}$. Polarization curves were started from cathodic to the anodic direction and were approved by sweeping the electrode potential mechanically from -300 to $+700 \mathrm{mV}$ segment to OCP at a scan rate of $0.5 \mathrm{mV} \mathrm{s}^{-1}$. Current corrosion density (icorr) magnitudes were verified from the acquired polarization bends utilizing Tafel extrapolation". IE\% and the $(\theta)$ were defined as:

$$
\begin{aligned}
& \text { IE } \%=\theta \times 100 \\
& \theta=\left[\left(i_{\text {corr }}-i_{\text {corr }(i n h)}\right) / i_{\text {corr }}\right]
\end{aligned}
$$

where $i_{\text {corr }}$ and $i_{\text {corr(inh) }}$ are the current unprotected and protected, individually.

The EIS tests were achieved at "OCP by analyzing a frequency response of the electrochemical system with the range extended from $0.01 \mathrm{~Hz}$ at minimum to $100,000 \mathrm{~Hz}$ at maximum frequency, and the excitation signal is $5 \mathrm{mV}$ sine wave. Gamry PCI4-G750 Potentiostat/Galvanostat/ ZRA. Echem Analyst V6.30" Software was applied for electrochemical data bends, fitting and graphing.

\section{Results and Discussion}

\section{1. (WL) tests.}

The WL of LCS specimen in 1.0M HCl solution, without and with altered cephalexin monohydrate drug doses (100-600 ppm), "were measured at altered times of dipping (30 to 180 min) at $25^{\circ} \mathrm{C}$. Fig. 1 signifies the WL of LCS in aggressive solution, without and with various cephalexin monohydrate drug doses. The attendance of the cephalexin monohydrate drug diminishes the corrosion rate (CR) of LCS in $\mathrm{HCl}$. Table 2 demonstrates the results obtained from WL tests for $\mathrm{LCS}$ in $\mathrm{HCl}$ attendance and lack of altered doses of the utilized cephalexin monohydrate drug as can see from Table 2 that IE \% raised and CR lowered with improving cephalexin monohydrate drug dose. This is due to the improving adsorption and raising coverage of cephalexin monohydrate drug on the surface of LCS" with improving cephalexin monohydrate drug dose [28].

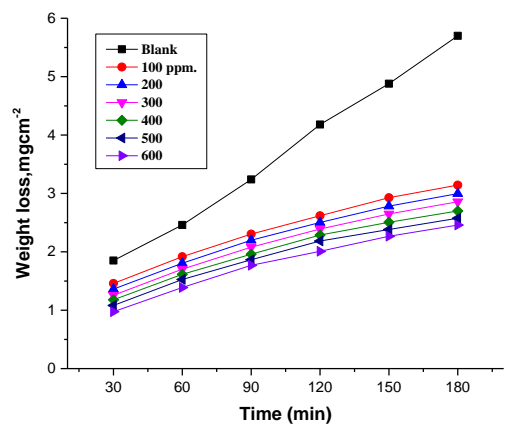

Figure 1. WL-time diagrams for the liquefaction of LCS with and without different doses of cephalexin monohydrate drug at $25^{\circ} \mathrm{C}$. 
Table 2. \% IE of LCS dissolution at $120 \mathrm{~min}$. Immersion in $1 \mathrm{M} \mathrm{HCl}$ with various doses of cephalexin monohydrate drug at $25^{\circ} \mathrm{C}$.

\begin{tabular}{c|c|c}
$\begin{array}{c}\text { Concentration } \\
\text { (ppm) }\end{array}$ & $\begin{array}{c}\text { \%Inhibition } \\
\text { Cephalexin monohydrate drug }\end{array}$ & $\boldsymbol{\theta}$ \\
\hline 100 & 37.4 & 0.374 \\
\hline 200 & 40.1 & 0.401 \\
\hline 300 & 42.8 & 0.428 \\
\hline 400 & 45.7 & 0.457 \\
\hline 500 & 47.7 & 0.477 \\
\hline 600 & 51.9 & 0.519
\end{tabular}

\subsubsection{Adsorption isotherms.}

The best correlation between the experimental results and the isothermal functions was obtained in the temperature studied $\left(25^{\circ} \mathrm{C}\right)$ utilizing the Temkin isotherm adsorption [29-30], which is given by the following balance.

$$
\text { In } \mathrm{K} \mathrm{C}=\mathrm{a} \theta
$$

where $\mathrm{C}$ is cephalexin monohydrate drug dose, and $\mathrm{K}$ is the equilibrium of adsorption constant. It is well recognized that the $\left(\Delta \mathrm{G}^{\circ}\right.$ ads $)$ is related $(\mathrm{K})$ and $\Delta \mathrm{G}^{\circ}$ ads by the following equation [31]:

$$
\mathrm{K}=1 / 55.5 \exp \left[-\Delta \mathrm{G}^{\circ} \text { ads } / \mathrm{RT}\right]
$$

where "55.5 is the cephalexin monohydrate drug dose of water in mol $1^{-1}$. Fig. 2 signifies the design of $(\theta)$ versus $\log \mathrm{C}$ for the dissolution of $\mathrm{LCS}$ in $1.00 \mathrm{M} \mathrm{HCl}$ at $25{ }^{\circ} \mathrm{C}$. As can be realized from Fig. 2, the Temkin isotherm is the greatest one which elucidates the investigational results". Also, it is established that the kinetic-thermodynamic model of El-Awady et al. [32].

$$
\log (\theta / 1-\theta)=\log \mathrm{k}^{\prime}+\mathrm{y} \log \mathrm{C}
$$

$\mathrm{K}={ }^{\prime} \mathrm{K}^{\prime}{ }^{\prime}(1 / \mathrm{y})$, ' $\mathrm{K}^{\prime}$ is constant, and $1 / \mathrm{y}$ is the number of the surface-active sites engaged by one cephalexin monohydrate drug molecule. "Drawing $\log (\theta / 1-\theta)$ versus $\log \mathrm{C}$ for the cephalexin monohydrate drug for the dissolution of LCS in $1 \mathrm{M} \mathrm{HCl}$ at $25^{\circ} \mathrm{C}$ is specified in Fig. 3. The data of $\mathrm{K}$ and $\Delta \mathrm{G}^{\circ}$ ads measured by Temkin and from the kinetic model are specified in Table 3. In general, the $\Delta \mathrm{G}^{\circ}$ ads data obtained from El-Awady et al. model are similar to those Temkin isotherms. The $\Delta \mathrm{G}^{\mathrm{o}}$ ads sign had negative, which designate spontaneous of cephalexin monohydrate drug onto the surface of LCS [33-35]. The $\Delta \mathrm{G}^{\mathrm{o}}$ ads data gotten for the studied cephalexin monohydrate drug on LCS surface range from $31 \mathrm{~kJ} \mathrm{~mol}^{-1}$ ", representative both

\begin{tabular}{|c|c|c|c|c|c|}
\hline \multicolumn{3}{|c|}{ Kinetic model } & \multicolumn{3}{|c|}{ Temkin } \\
\hline $1 / \mathbf{y}$ & $\mathbf{K}$ & $-\Delta \mathbf{G}^{\mathbf{0}}$ ads. $\mathbf{k J} \mathbf{~ m o l}^{-1}$ & $\mathbf{a}$ & $\mathbf{K}$ & $-\Delta \mathbf{G}_{\text {ads. }}^{\mathbf{0}}, \mathrm{kJ} \mathrm{mol}^{-1}$ \\
\hline 2.31 & 1.44 & $\mathbf{3 1 . 2 5}$ & 12.81 & 1.16 & 31.60 \\
\hline
\end{tabular}
physical and chemical adsorption [36].

Table 3. Parameters obtained from Adsorption isotherm (Kinetic model and Temkin) at $25^{\circ} \mathrm{C}$.

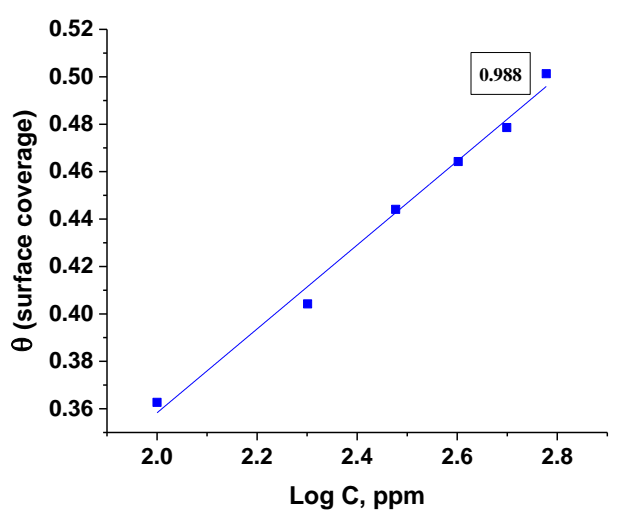

Figure 2. Diagrams fitting of dissolution data for LCS $1 \mathrm{M} \mathrm{HCl}$ to Temkin adsorption isotherm at $25^{\circ} \mathrm{C}$. 


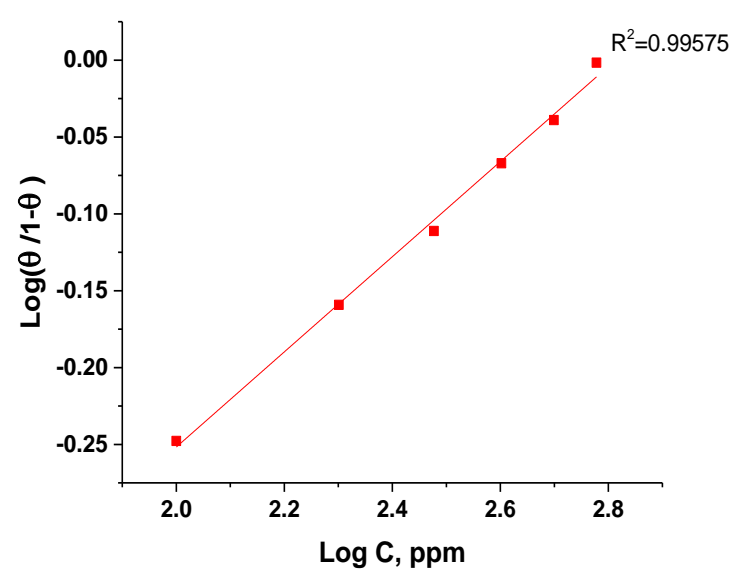

Figure 3. Diagrams fitting of dissolution data for LCS $1 \mathrm{M} \mathrm{HCl}$ in the existence of cephalexin monohydrate drug to the kinetic model at $25^{\circ} \mathrm{C}$.

\subsubsection{Kinetic parameters.}

The dissolution of LCS in $1 \mathrm{M} \mathrm{HCl}$ existence and nonexistence various doses of the cephalexin monohydrate drug $(100-600 \mathrm{ppm})$ at temperatures range $\left(25-45^{\circ} \mathrm{C}\right)$ was deliberately utilizing WL test. "The \%IE data at various temperatures were presented in Table 4 The outcome data exposed that the degree of the \%IE improved with raising the dose of the cephalexin monohydrate drug and reduced with raising temperature [37] whereas the \%IE is significantly lowered at a higher temperature. The reduction of the \%IE with improving the temperature is expressive of physical adsorption of the utilized cephalexin monohydrate drug on the surface of LCS".

Table 4. IE \% of LCS dissolution at $120 \mathrm{~min}$. Immersion in $1 \mathrm{HCl}$ attendance and lack of altered doses of cephalexin monohydrate drug at different temperatures.

\begin{tabular}{c|c|c|c|c}
\multirow{2}{*}{$\begin{array}{c}\text { Concentration } \\
(\mathbf{p p m})\end{array}$} & \multicolumn{4}{|c}{ IE \% } \\
\cline { 2 - 5 } & $\mathbf{3 0}^{\circ} \mathbf{C}$ & $\mathbf{3 5}^{\circ} \mathbf{C}$ & $\mathbf{4 0}^{\circ} \mathbf{C}$ & $\mathbf{4 5}^{\circ} \mathbf{C}$ \\
\hline 100 & 30.4 & 20.9 & 13.1 & 6.5 \\
\hline 200 & 33.0 & 23.8 & 15.6 & 8.5 \\
\hline 300 & 35.2 & 26.9 & 17.7 & 10.4 \\
\hline 400 & 38.5 & 29.7 & 20.5 & 12.7 \\
\hline 500 & 41.0 & 32.0 & 23.0 & 14.8 \\
\hline 600 & 43.9 & 34.4 & 25.2 & 17.1
\end{tabular}

The impact of temperature on both corrosion and corrosion protection of LCS in an aggressive environment in existence and lack of altered dose of cephalexin monohydrate drug at various temperatures ranging from $25^{\circ} \mathrm{C}$ to $45^{\circ} \mathrm{C}$ was deliberately utilizing WL. The CR improves with improving temperature both in uninhabited and inhabited acid. The parameters of activation for the liquefaction technique measured from the Arrhenius plot as next [38]:

$$
\mathrm{k}=\mathrm{A} \exp \left(-\mathrm{E}_{\mathrm{a}}^{*} / \mathrm{RT}\right)
$$

$E^{*}{ }_{a}$ can be obtained from the slope of " $\log \left(k_{\text {corr }}\right)$ against $1 / T$ plots attendance and lack of altered doses of the cephalexin monohydrate drug as obtainable in Fig. 4. Data of $\mathrm{E}_{\mathrm{a}}^{*}$ are described in Table $5 \mathrm{E}^{*}$ a has higher data in the existence of the cephalexin monohydrate drug than that in its nonexistence. This has attributed the physical adsorption of cephalexin monohydrate drugs on LCS surface [39]. The transition state theory was utilized to calculate the $\left(\Delta \mathrm{S}^{*}\right)$ and $\left(\Delta \mathrm{H}^{*}\right)$ Fig. 5 . The change data of $\left(\Delta \mathrm{S}^{*}\right)$ and $\left(\Delta \mathrm{H}^{*}\right)$ " can be measured by utilizing the formula:

$$
\mathrm{k}_{\mathrm{corr}}=(\mathrm{RT} / \mathrm{Nh}) \exp \left({ }^{\left.\Delta \mathrm{S}^{*} / \mathrm{R}\right)} \exp ^{\left(-\Delta \mathrm{H}^{*} / \mathrm{RT}\right)}\right.
$$


$\Delta \mathrm{H}^{*}$ and $\Delta \mathrm{S}^{*}$ were designed by applying the next balance [40-42]:

$$
\begin{gathered}
\Delta H^{*}=E^{*}-R T \\
\Delta S^{*}=\left(\Delta H^{*}-\Delta G^{*}\right) / T
\end{gathered}
$$

The sign of $\Delta \mathrm{H}^{*}$ is positive and high in the existence of the cephalexin monohydrate drug over that of the unprotected solution. "This indicates that the energy barrier of the dissolution reaction in the existence of the investigated cephalexin monohydrate drug increases. Conversely, $\Delta \mathrm{S}^{*}$ data are lesser and have negative data in the existence of the cephalexin monohydrate drug; this means that the appending of this cephalexin monohydrate drug causes a lower in the disordering in going from reactants to the activated complexes" [43-44].

Table 5. Kinetic Parameters for the utilized cephalexin monohydrate drug on the dissolution of LCS in $1.00 \mathrm{M}$

\begin{tabular}{|c|c|c|c|}
\hline Concentration, (ppm) & $\mathbf{E}_{\mathrm{a}}{ }^{*}, \mathrm{~kJ} \mathrm{~mol}^{-1}$ & $\Delta \mathbf{H}^{*}, \mathbf{k J} \mathbf{~ m o l}^{-1}$ & $-\Delta \mathbf{S}^{*}, \mathbf{k}^{-1} \mathbf{J} \mathbf{m o l}^{-1}$ \\
\hline 100 & 61.5 & 62.0 & 20.9 \\
\hline 200 & 64.5 & 62.2 & 23.8 \\
\hline 300 & 64.9 & 63.2 & 26.9 \\
\hline 400 & 65.4 & 63.3 & 29.7 \\
\hline 500 & 65.9 & 64.8 & 32.0 \\
\hline 600 & 66.2 & 65.1 & 34.4 \\
\hline
\end{tabular}
$\mathrm{HCl}$ solution.

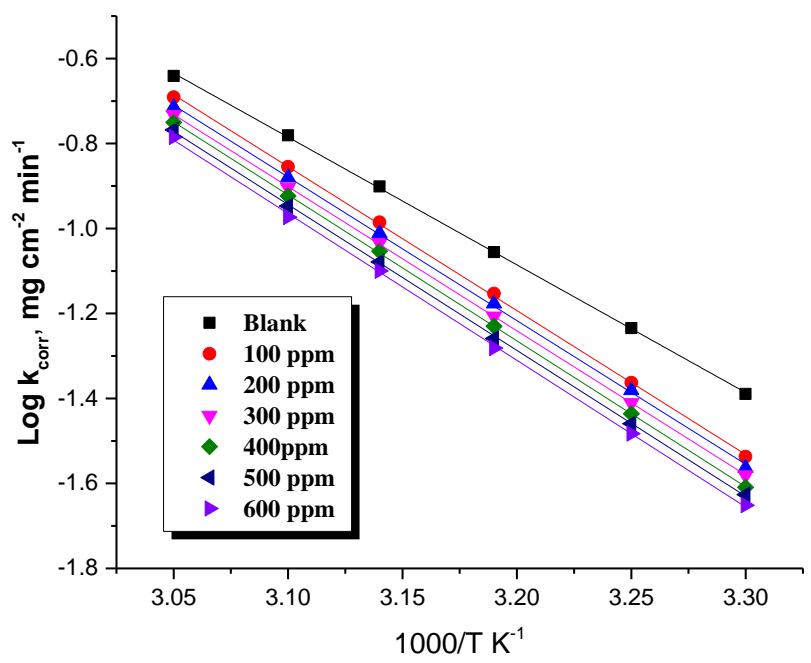

Figure 4. $\log$ k- 1000/T bends for LCS dissolution existence and nonexistence of altered doses of cephalexin monohydrate drug.

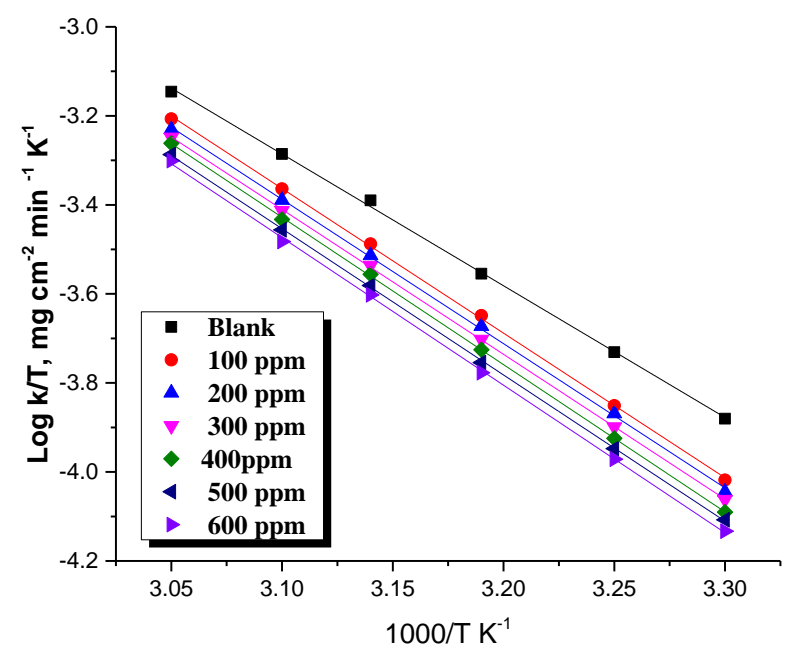

Figure 5. $\log (\mathrm{k} / \mathrm{T})$ vs. $(1000 / \mathrm{T})$ bends for LCS dissolution existence and nonexistence of altered doses of cephalexin monohydrate drug. 


\subsection{Polarization tests $(P P)$.}

Fig. 6 demonstration PP bends registered for LCS in $1.00 \mathrm{M} \mathrm{HCl}$ solutions attendance and nonattendance of an altered dose of cephalexin monohydrate drug at $25^{\circ} \mathrm{C}$. "With the increment of the dose of cephalexin monohydrate drug diagrams shifts both anodic and cathodic sections to the lesser data of $\mathrm{i}_{\text {corr, }}$ which leads to dropping in the CR. The PP bends recognized in Table 6 as the alternation of the data of (log $\left.i_{\text {corr }}\right)$ with the $\left(E_{c o r r}\right),(\beta a, \beta c),(C . R$.$) ,$ $(\theta)$ and $(\% \mathrm{IE})$. This means that cephalexin monohydrate drug hinders both cathodic and anodic reactions of LCS in $\mathrm{HCl}$ medium. The slopes of anodic and cathodic Tafel lines ( $\beta \mathrm{a}$ and $\beta \mathrm{c})$, were lightly varied with the rasing the dose of cephalexin monohydrate drug". This designates that a cephalexin monohydrate drug inhibitor signifies as mixed-type inhibitors [45].

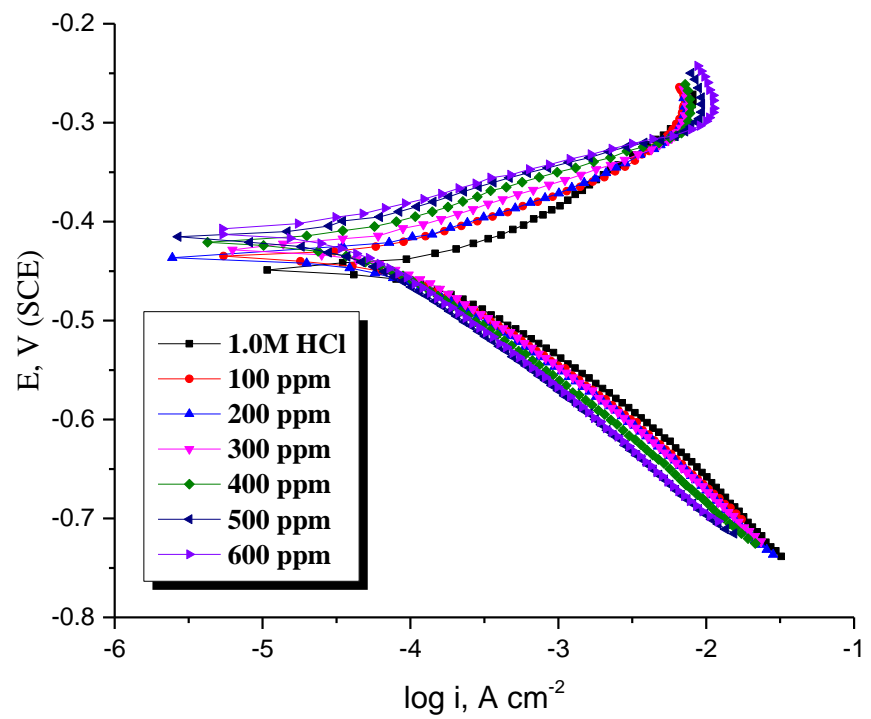

Figure 6. PP bends for LCS existence and nonexistence of altered dose of cephalexin monohydrate drug at $25^{\circ} \mathrm{C}$.

Table 6. PP values of LCS in $1.0 \mathrm{M} \mathrm{HCl}$ in existence and nonexistence of altered dose of cephalexin monohydrate drug at $25^{\circ} \mathrm{C}$.

\begin{tabular}{|c|c|c|c|c|c|c|c|c|c|}
\hline $\begin{array}{c}\text { [Inh. }] \\
\text { ppm }\end{array}$ & $\begin{array}{c}\text {-Eoc } \\
\text { mV vs.SCE }\end{array}$ & $\begin{array}{c}-E_{\text {corr }} \\
m V \text { vs.SCE }\end{array}$ & $\begin{array}{c}\text { jeorr } \\
\mu \mathrm{A}^{\mathbf{c m}^{-2}}\end{array}$ & $\begin{array}{c}\beta_{c} \\
m \text { dec }^{-1}\end{array}$ & $\begin{array}{c}\boldsymbol{\beta}_{\mathrm{a}} \\
\mathrm{mV} \mathbf{d e c}^{-1}\end{array}$ & $\begin{array}{c}R_{p} \\
\Omega \mathbf{c m}^{2}\end{array}$ & $\underset{\left(\mathrm{mmyr}^{-1}\right)}{\text { C.R. }}$ & $\begin{array}{c}\text { IE\%, } \\
\text { jeorr }\end{array}$ & $\begin{array}{c}\text { IE\%, } \\
\mathbf{R}_{\mathbf{p}}\end{array}$ \\
\hline blank & 438 & 449 & 199.1 & 126 & 94 & 117.6 & 2.311 & -- & -- \\
\hline 100 & 429 & 442 & 126.5 & 116 & 64 & 141.8 & 1.468 & 36.5 & 17.4 \\
\hline 200 & 436 & 436 & 120 & 114 & 63 & 147.1 & 0.974 & 39.7 & 20.1 \\
\hline 300 & 423 & 427 & 116 & 115 & 61 & 149.4 & 0.874 & 41.7 & 21.3 \\
\hline 400 & 424 & 422 & 107 & 112 & 62 & 162.2 & 0.648 & 46.3 & 27.5 \\
\hline 500 & 443 & 434 & 97.2 & 115 & 60 & 176.4 & 0.436 & 51.2 & 33.3 \\
\hline 600 & 399 & 436 & 94.1 & 113 & 63 & 186.9 & 0.402 & 52.8 & 37.1 \\
\hline
\end{tabular}

\subsubsection{Synergistic effect.}

The rise in \%IE of cephalexin monohydrate drug in the existence of some anions has been experiential by numerous detectives [46] and was recognized as a synergistic effect. "Test to improve the effectiveness of the investigated cephalexin monohydrate drug by appending of KI were carried out utilizing PP tests. Fig. 7 shows PP bends for LCS in $1.00 \mathrm{M} \mathrm{HCl}$ in existence and lack of $600 \mathrm{ppm}$ of cephalexin monohydrate drug without and with different doses $\left(1 \times 10^{-4}, 1 \times 10^{-3}, 1 \times 10^{-2} \mathrm{M}\right)$ of $\mathrm{KI}$ at $25^{\circ} \mathrm{C}$ as an example. The obtained electrochemical values (Eoc, $E_{\text {corr, }} i_{\text {corr }}, \beta_{c}, \beta_{a}, R_{p}$, and $\%$ IE) are shown in Table 7 . Results revealed in Tables 7 exposed that the existence of various doses of KI improves the lowering of $i_{\text {corr }}$ values for LCS 
in $1.0 \mathrm{M} \mathrm{HCl}$ and the lessening in the $\mathrm{CR}$ with improving the dose of $\mathrm{KI}$ representative that appending of KI increases the protecting action of the cephalexin monohydrate drug. The detected synergistic influence results from rising surface coverage arising from ion-pair interaction between $\mathrm{I}^{-}$anion and Cephalexin monohydrate drugs. There are altered schools of thought [47] on the actual role of the anions as respects increase the adsorption of the cephalexin monohydrate drug. The increment in the \%IE of cephalexin monohydrate drug on the appending of iodide ions during LCS was qualified for the mechanism by Wu et al. [48] while the results of Oguzie et al. [49] and other authors [47]. Stabilization of the iodide ions adsorbed with cephalexin monohydrate drug cations indications higher surface coverage and thus increase inhibition productivity". The better \%IE caused by the appending of iodide ions to cephalexin monohydrate drugs is only due to the synergistic effect.

Table 7. Synergistic effect of various doses of KI with $600 \mathrm{ppm}$ of cephalexin monohydrate drug on the PP

\begin{tabular}{|c|c|c|c|c|c|c|c|c|c|}
\hline $\begin{array}{l}{[\mathrm{KI}]} \\
\mathbf{M}\end{array}$ & $\begin{array}{l}\text {-EoC } \\
\text { mV }\end{array}$ & $\begin{array}{c}-\mathbf{E}_{\text {corr }} \\
\mathrm{mV}\end{array}$ & $\begin{array}{c}\begin{array}{c}\mathbf{j}_{\text {corr }} \\
\mu \mathrm{A} \mathrm{cm}^{-2}\end{array} \\
\end{array}$ & $\begin{array}{c}-\beta_{c} \\
m V \operatorname{dec}^{-1}\end{array}$ & $\begin{array}{c}\beta_{\mathrm{a}} \\
\mathrm{mV} \operatorname{dec}^{-1}\end{array}$ & $\begin{array}{c}\mathbf{R}_{\mathbf{p}} \\
\text { ohm } \text { cm }^{2}\end{array}$ & $\begin{array}{c}\text { CR } \\
\text { mm yr } \mathbf{r r}^{-1} \\
\end{array}$ & $\begin{array}{c}\text { IE\%, } \\
\text { jcorr }\end{array}$ & IE $\%, \mathbf{R}_{p}$ \\
\hline- & 399 & 436 & 94.1 & 187 & 63 & 186.9 & 1.092 & 52.8 & 37.1 \\
\hline $1 \times 10^{-4}$ & 350 & 379 & 31.2 & 103 & 64 & 549.6 & 0.363 & 84.3 & 78.6 \\
\hline $1 \times 10^{-3}$ & 307 & 344 & 18.4 & 110 & 72 & 1026.0 & 0.213 & 90.8 & 88.5 \\
\hline $1 \times 10^{-2}$ & 238 & 307 & 18.0 & 139 & 87 & 1292.0 & 0.209 & 91.0 & 90.9 \\
\hline
\end{tabular}

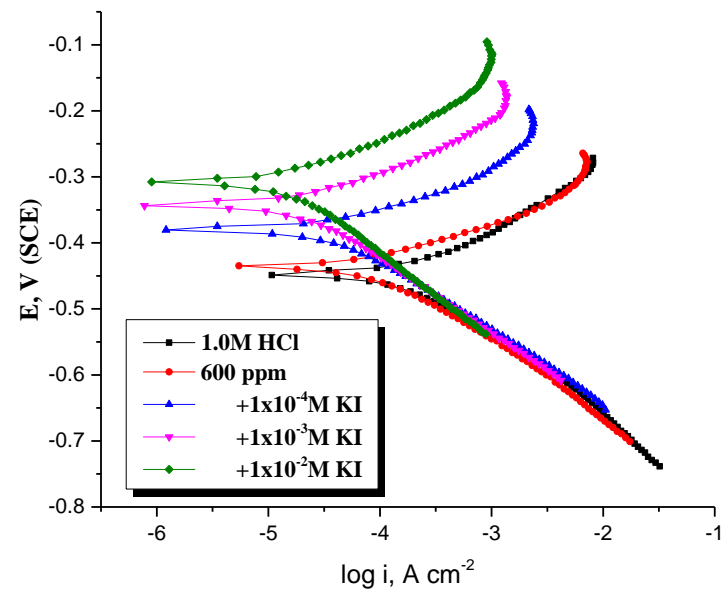

Figure 7. $\mathrm{PP}$ diagrams of LCD in $1.0 \mathrm{M} \mathrm{HCl}$ existence and nonexistence of $600 \mathrm{ppm}$ of cephalexin monohydrate drug and an altered dose of $\mathrm{KI}$ at $25^{\circ} \mathrm{C}$.

\subsection{EIS tests.}

The dissolution of LCS in $1 \mathrm{M} \mathrm{HCl}$ in the existence of cephalexin monohydrate drug was examined by EIS test at $25^{\circ} \mathrm{C}$ after 20 min dipping. "Nyquist and Bode bend in the attendance, and lack of altered doses of cephalexin monohydrate drug exist in Figs. 8 and 9, correspondingly. It seems that all Nyquist bends show a single capacitive loop, both in unprotected and protected solutions. The EIS data of LCS in $1 \mathrm{M} \mathrm{HCl}$ are investigated in terms of an equivalent circuit model (Fig. 10) [50].

The circuit has the solution resistance $\mathrm{R}_{\mathrm{s}}$ and the double layer capacitance $\mathrm{C}_{\mathrm{dl}}$ that put parallel to $\mathrm{R}_{\mathrm{ct}}$ [51]. $\mathrm{C}_{\mathrm{dl}}$, for a circuit including a CPE calculated from the following balance [52-53]:

$$
\mathrm{C}_{\mathrm{dl}}=\left(1 / 2 \pi \mathrm{f}_{\max } \mathrm{R}_{\mathrm{ct}}\right)
$$

where $f_{\max }$ is maximum frequency. Table 8 includes the obtained impedance data. As shown, $\mathrm{R}_{\mathrm{ct}}$ rises, and hence \% IE increases, with the increase in cephalexin monohydrate drug concentration, while $\mathrm{C}_{\mathrm{dl}}$ lowered. That is because the adsorption of the cephalexin monohydrate 
drug on the LCS surface, forming a film on it". The ( $\%$ IE) and $\theta$ were founded from the next balance:

$$
\mathrm{IE} \%=\theta \times 100=\left[\left(\mathrm{R}_{\mathrm{ct}(\mathrm{inh})}-\mathrm{R}_{\mathrm{ct}}\right) / \mathrm{R}_{\mathrm{ct}(\mathrm{inh})}\right] \times 100
$$

Table 8. EIS parameters technique for the dissolution of LCS at different doses of cephalexin monohydrate

\begin{tabular}{|c|c|c|c|c|c|}
\hline \multicolumn{6}{|c|}{ drugs at $25^{\circ} \mathrm{C}$. } \\
\hline $\begin{array}{l}{[\text { Inh. }]} \\
\text { ppm }\end{array}$ & $\begin{array}{c}\mathrm{C}_{\mathrm{dl}} \\
\mu \mathrm{F} \mathbf{~ c m}^{-2}\end{array}$ & $\begin{array}{l}\text {-Phase } \\
\text { degree }\end{array}$ & $\underset{\text { ohm } \mathbf{c m}^{2}}{\mathbf{R}_{\mathrm{ct}}}$ & $\boldsymbol{\theta}$ & IE\% \\
\hline $1.0 \mathrm{M} \mathrm{HCl}$ & 71.4 & 71.2 & 234.6 & $\begin{array}{ll}--- \\
\end{array}$ & ---- \\
\hline 300 & 66.9 & 71.7 & 496.8 & 0.528 & 52.8 \\
\hline 400 & 64.5 & 71.6 & 527.3 & 0.555 & 55.5 \\
\hline 500 & 53.8 & 73.0 & 647.2 & 0.638 & 63.8 \\
\hline 600 & 53.9 & 73.1 & 710.4 & 0.670 & 67.0 \\
\hline
\end{tabular}

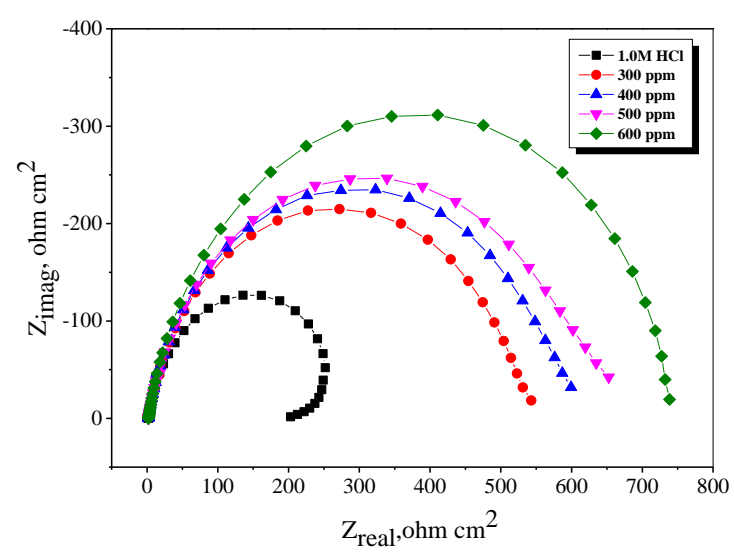

Figure 8. The Nyquist bends for dissolution of LCD in $1.0 \mathrm{M} \mathrm{HCl}$ in existence and nonexistence of altered of cephalexin monohydrate drug at $25^{\circ} \mathrm{C}$.

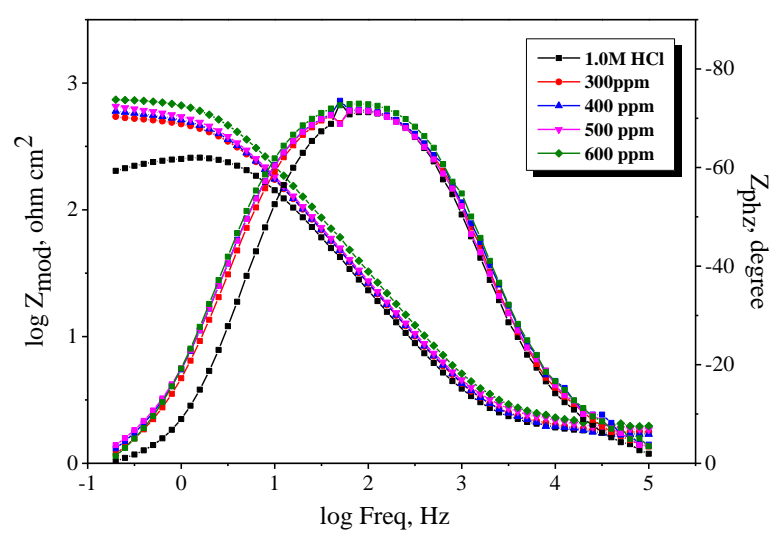

Figure 9. The Bode bends for dissolution of LCD in $1.0 \mathrm{M} \mathrm{HCl}$ in existence and nonexistence of altered of cephalexin monohydrate drug at $25{ }^{\circ} \mathrm{C}$.

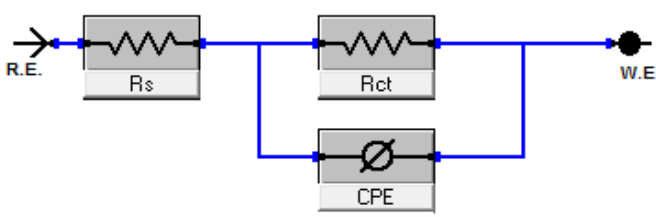

Figure 10. The equivalent circuit model used to fit the experimental results.

\subsection{Quantum chemical calculation.}

The capability of quantum calculations practical to the cephalexin monohydrate drug to predict their productivities as corrosion drug was studied. "Fig. 11 and Table 9 demonstrations the quantum parameters (EHumo, Elumo) and the energy band gap 
$(\Delta \mathrm{E}=\mathrm{Elumo}-\mathrm{Ehomo})$ is also listed. Еномо is related to the electron-donating ability of the molecule. The high value of Еномо is pointed to the affinity of the cephalexin monohydrate drug to give electrons to be suitable for the molecules acceptor, which devising small energy and empty molecular orbitals [54]. The protection efficiencies improve with the upper or less negative Еномо energies, with raising data of the dipole moment with diminishing the data of $\Delta \mathrm{E}$ (energy gap) $[55,56]$ and the stronger interaction among cephalexin monohydrate and LCD surface. The IE values increase with the lower ionization potential of the cephalexin monohydrate drug molecule, which means that the cephalexin monohydrate drug acts as an electron donor when blocking the dissolution reaction sites" [57].

Table 9. Quantum chemical parameters for $600 \mathrm{ppm}$ of cephalexin monohydrate drug for the liquefaction of LCS.

\begin{tabular}{l|c|c|c|c}
$\begin{array}{l}\text { cephalexin } \\
\text { monohydrate }\end{array}$ & $\begin{array}{c}-\mathbf{E H O M O}_{\text {Hog }} \\
\text { drug }\end{array}$ & $\begin{array}{c}-\mathbf{E}_{\text {LUMo }} \\
\mathbf{e V}\end{array}$ & $\begin{array}{c}\Delta \mathbf{E} \\
\mathbf{e V}\end{array}$ & $\begin{array}{c}\boldsymbol{\mu} \\
\text { Debye }\end{array}$ \\
\cline { 2 - 4 } & 7.857 & 1.025 & 6.832 & 28.164
\end{tabular}
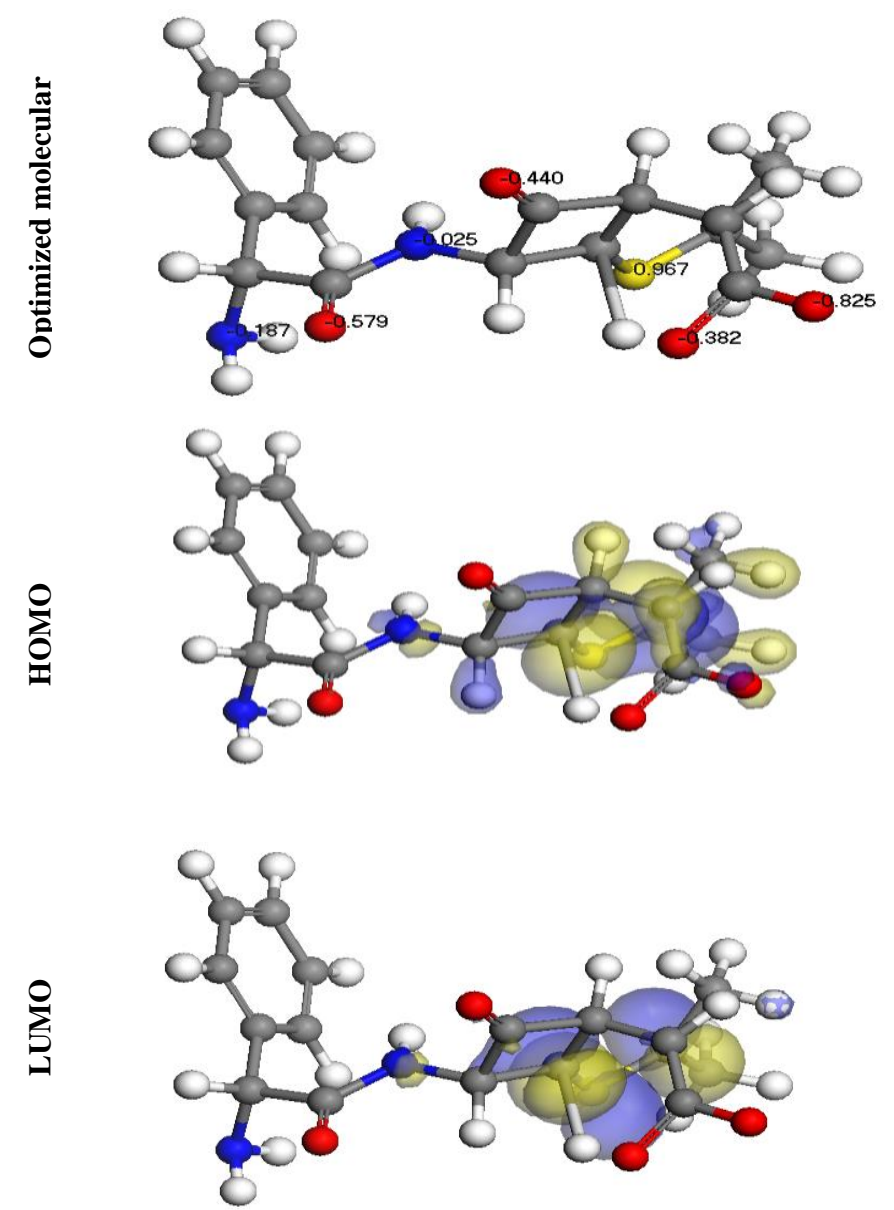

Figure 11. Optimized molecular structure and (HOMO and LUMO) of cephalexin monohydrate drug.

\subsection{Mechanism of corrosion inhibition.}

The cephalexin monohydrate drug-containing $\mathrm{S}, \mathrm{N}$, and $\mathrm{O}$ are recognized to be an effective drug. "Its efficiency relies on the electron density at the functional groups. The corrosion protection of the cephalexin monohydrate drug can be qualified for the existence of heteroatom and $\pi$ electrons on the benzene ring. In the aqueous acidic environment, cephalexin monohydrate drug occurs either as neutral molecules or in the form of cations (protonated form). Fig. 12 show the protonated cephalexin monohydrate drug may adsorb through 
electrostatic interactions among positively charged molecules and the negatively charged LCS surface. In other words, there may be a synergism between $\mathrm{Cl}^{-}$and cephalexin monohydrate drugs, which improves the inhibitive ability of the cephalexin monohydrate drug. When the protonated form is adsorbed on the LCS surface, a coordinate bond may be formed by the partial transference of electrons from $\mathrm{N}, \mathrm{O}$, and $\mathrm{S}$ atoms to the metal surface [58-59]. In addition, owing to lone-pair electrons of $\mathrm{N}, \mathrm{O}$, and $\mathrm{S}$ atoms in the cephalexin monohydrate drug or the protonated form may combine with freshly generated $\mathrm{Fe}^{2+}$ ions on LCS" surface forming metal drug complexes

$$
\begin{aligned}
& \mathrm{Fe} \rightarrow \mathrm{Fe}^{2+}+2 \mathrm{e} \\
& \mathrm{Inh}+\mathrm{Fe}^{2+} \leftrightarrow[\mathrm{Inh}-\mathrm{Fe}]^{2+} \\
& {[\mathrm{Inh}]^{\mathrm{n}+}+\mathrm{Fe}^{2+} \leftrightarrow[\mathrm{Inh} \text { n- Fe }]^{(2+\mathrm{n})+}}
\end{aligned}
$$

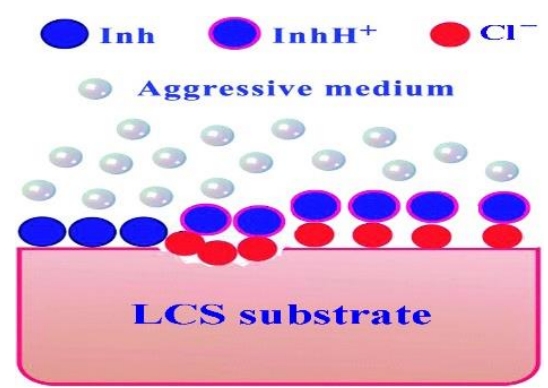

Figure 12. Proposed mechanism for the adsorption of cephalexin monohydrate drug on the LCS surface in $\mathrm{HCl}$ medium.

\section{Conclusions}

Cephalexin monohydrate drug has verified to be an environmentally friendly inhibitor for the dissolution of LCS in $1 \mathrm{M} \mathrm{HCl}$ solution. This cephalexin monohydrate drug acts as a mixed kind inhibitor, and IE\% was established to rise by improving the cephalexin monohydrate dose and reduction with temperature increasing. The inhibition action of Cephalexin monohydrate drug inhibitor due to the creation of adsorbed insoluble complex on LCS. The adsorption technique obeys Temkin and Kinetic model isotherm. The outcome data from EIS test runs parallel with PP tests, prove the creation of a protective film on the surface of LCS surface in $1.0 \mathrm{M} \mathrm{HCl}$. The KI added to raise the protecting action of the cephalexin monohydrate drug. The IE improves with raising the energy of the highest occupied molecular orbital (Еномо), which means that the Cephalexin monohydrate drug acts as an electron donor when blocking the dissolution reaction sites.

\section{Funding}

This research received no external funding.

\section{Acknowledgments}

All our gratitude to the anonymous referees for their careful reading of the manuscript and valuable comments, which helped in shaping this paper to the present form. We thank all laboratory staff of corrosion chemistry from the University of Mansoura (Egypt) for their kind cooperation. 


\section{Conflicts of Interest}

The authors declare no conflict of interest.

\section{References}

1. Panossian, Z.; Almeida, N.L.D.; Sousa, R.M.F.D.; Pimenta, G.D.S.; Marques, L.B.S. Corrosion of carbon steel pipes and tanks by concentrated sulfuric acid: a review. Corros. Sci. 2012, 58, 1-11, https://doi.org/10.1016/j.corsci.2012.01.025.

2. Verma, C.; Quraishi M.A.; Ebenso E.E. Microwave and ultrasound irradiations for the synthesis of environmentally sustainable corrosion inhibitors: An overview. Sustainable Chemistry and Pharmacy 2018, 10, 134-147, https://doi.org/10.1016/j.scp.2018.11.001.

3. Afia, L.; Salghi, R.; Bammouetal, L. Anti-corrosive properties of Argan oil on C38 steel in molar $\mathrm{HCl}$ solution. Journal of Saudi Chemical Soci. 2014, 18, https://doi.org/10.1016/j.jscs.2011.05.008.

4. Emori, W.; Zhang, R.H.; Okafor, P.C.; Zheng, X.W.; He, T.; Wei, K.; Lin, X.Z.; Cheng, C.R. Adsorption and corrosion inhibition performance of multi-phytoconstituents from Dioscorea septemloba on carbon steel in acidic media: Characterization, experimental and theoretical studies. Colloids and Surfaces A: Physicochemical and Engineering Aspects. 2020, 590, 1-13, https://doi.org/10.1016/j.colsurfa.2020.124534.

5. Ahmed, S.K.; Ali, W.B.; Khadom, A.A. Synthesis and investigations of heterocyclic compounds as corrosion inhibitors for mild steel in hydrochloric acid. International Journal of Industrial Chemistry 2019, 10, 159-173, https://doi.org/10.1007/s40090-019-0181-8.

6. Hou, B.S.; Zhang, Q.H.; Li, Y.Y.; Zhu, G.Y.; Liu, H.F.; Zhang, G.A. A pyrimidine derivative as a high efficiency inhibitor for the corrosion of carbon steel in oilfield produced water under supercritical CO2 conditions. Corros. Sci. 2020, 164, 1-18, https://doi.org/10.1016/j.corsci.2019.108334.

7. Popoola, L.T. Progress on pharmaceutical drugs, plant extracts and ionic liquids as corrosion inhibitors. Heliyon. 2019, 5, https://doi.org/10.1016/j.heliyon.2019.e01143.

8. Aoun, S.B.; Messali, M. Microwave-assisted synthesis of green inhibitor for carbon steel acid corrosion. Int. J. Electrochem. Sci. 2018, 13, 3757-3776, https://doi.org/10.20964/2018.04.55.

9. Kamal, C.; Sethuuraman, M.G. Caulerpin-A bis-Indole alkaloid as a green inhibitor for the corrosion of mild steel in $1 \mathrm{M} \mathrm{HCl}$ solution from the marine Alga Caulerpa racemose. Industrial and Engineering Chemistry Reserch 2012, 51, 10399-10407, https://doi.org/10.1021/ie3010379.

10. Bidi, M.A.; Azadi, M.; Rassouli, M. A new green inhibitor for lowering the corrosion rate of carbon steel in $1 \mathrm{M} \mathrm{HCl}$ solution: Hyalomma tick extract. Materials today communications 2020, 24, 1-9, https://doi.org/10.1016/j.mtcomm.2020.100996.

11. Gece, G. Drugs, A review of promising novel corrosion inhibitors. Corros. Sci. 2011, 53, 3873-3898, https://doi.org/10.1016/j.corsci.2011.08.006.

12. Idouhli, R.; Koumya, Y.; Khadiri, M.; Aityoub, A.; Abouelfida, A.; Benyaich, A. Inhibitory effect of Senecio anteuphorbium as green corrosion inhibitor for S300 steel. Int. J. Ind. Chem. 2019, 10, 133-143, https://doi.org/10.1007/s40090-019-0179-2.

13. Fouda, A.S.; Eissa, M.; El-Hossiany, A. Ciprofloxacin as Eco-Friendly Corrosion Inhibitor for Carbon Steel in Hydrochloric Acid Solution. Int. J. Electrochem. Sci. 2018, 13, 11096-11112, https://doi.org/10.20964/2018.11.86.

14. Fouda, A.S.; El-Ewady, G.; Ali, A.H. Modazar as promising corrosion inhibitor of CS in hydrochloric acid solution. Green chemistry letters and reviews 2017, 10, 88-100, https://doi.org/10.1080/17518253.2017.1299228.

15. Attia, E.M. Expired Farcolin Drug as Corrosion Inhibitor for CS in 1M HCl Solution. J. Basic. Appl. Chem. 2015, 5, 1-15.

16. Akpan, I.A.; Offiong, N.O. Inhibition of mild steel corrosion in hydrochloric acid solution by Ciprofloxacin drug. International Journal of Corrosion 2013, 2013, 1-5, https://doi.org/10.1155/2013/301689.

17. Kushwah, R.; Pathak, R.K. Inhibition of Mild Steel Corrosion in 0.5 M Sulphuric Acid Solution by Aspirin Drug. International Journal of Emerging Technology and Advanced Engineering 2014, 4, 880-884, https://doi.org/10.1109/vppc.2009.5289563.

18. Shainy, K.M.; Rugmini Ammal, P.; Unni, K.N.; Benjamin, S.; Joseph, A. Surface Interaction and Corrosion Inhibition of Mild Steel in Hydrochloric Acid Using Pyoverdine, an Eco-Friendly Bio-molecule. Journal of Bio- and Tribo-Corrosion 2016, 2, https://doi.org/10.1007/s40735-016-0050-3.

19. Gholamhosseinzadeh, M.R.; Aghaie, H.; Shahidi Zandi, M.; Giahi, M. Rosuvastatin drug as a green and effective inhibitor for corrosion of mild steel in $\mathrm{HCl}$ and $\mathrm{H} 2 \mathrm{SO} 4$ solutions. J. Mater. Res. Technol. 2019, 8, 5314-5324, https://doi.org/10.1016/j.jmrt.2019.08.052.

20. Fouda, A.S.; Rashwan, S.; Ibrahim, H.; Atef, M. Cialis (Tadalafil) drug as save corrosion inhibitor for Zn in hydrochloric acid solution. Journal of Applicable Chemistry 2017, 6, 458-475, https://doi.org/10.1155/2012/573964.

21. Kolo, AM.; Sani, UM.; Kutama, IU.; Usman, Umar. Adsorption and Inhibitive Properties of Januvia for the Corrosion of $\mathrm{Zn}$ in 0.1 M HCl. The Pharmaceutical and Chemical Journal 2016, 3, 109-119.

https://biointerfaceresearch.com/ 
22. Ameh, P.O.; Sani, U.M. Cefuroxime Axetil: A Commercially Available Pro-Drug as Corrosion Drug for Aluminum in Hydrochloric Acid Solution. Journal of Heterocyclics 2015, 1, 2-6, https://doi.org/10.33805/2639-6734.101.

23. Martinez, S.; Stern, I. Inhibitory mechanism of low-CS corrosion by mimosa tannin in sulphuric acid solutions. J. Appl Electrochem. 2001, 31, 973- 978, https://doi.org/10.1023/A:1017989510605.

24. Fouda, A.S.; El-Awady, G.Y.; El Behairy, W.T. Prosopis juliflora Plant Extract as Potential Corrosion Inhibitor for Low-Carbon Steel in $1 \mathrm{M} \mathrm{HCl} \mathrm{Solution.} \mathrm{Journal} \mathrm{of} \mathrm{Bio-} \mathrm{and} \mathrm{Tribo-Corrosion} \mathrm{2017,} \mathrm{4,}$ https://doi.org/10.1007/s40735-017-0124-X.

25. Aharoni, C.; Ungarish, M. Kinetics of activated chemisorptions. Part 2. Theoretical models. J. Chem. Soc. Faraday Trans. 1977, 73, 456-464, https://doi.org/10.1039/F19777300456.

26. Zhang, S.; Hou, L.; Du, H.; Wei, H.; Liu, B.; Wei, Y. A study on the interaction between chloride ions and $\mathrm{CO}_{2}$ towards carbon steel corrosion. Corrosion Science 2020, 167, https://doi.org/10.1016/j.corsci.2020.108531.

27. Samide, A.; Tutunaru, B.; Negrila, C. Corrosion Inhibition of Carbon Steel in Hydrochloric Acid solution using a Sulfa Drug. Chem. Biochem. Eng. Q. 2011, 25, 299-308.

28. Baymou, Y.; Bidi, H.; Ebn Touhami, M.; Allam, M.; Rkayae, M.; Belakhmima, R.A. Corrosion Protection for Cast Iron in Sulfamic Acid Solutions and Studies of the Cooperative Effect Between Cationic Surfactant and Acid Counterions. Journal of Bio- and Tribo-Corrosion 2018, 4, https://doi.org/10.1007/s40735-0180127-2.

29. Ve, S.; Ligandlarını, A.; Sekiz, İ.; Üzerine, K.; Çalışmalar, T.; erkan kariper, S.; Sultan, E.; Kariper; Sayin, K.; Karakaş, D. Theoretical Studies on Eight Oxovanadium(IV) Complexes with Salicylaldehyde and Aniline Ligands introduction. Hacet. J. Biol. Chem. 2014, 42, 337-342.

30. Ibrahim, M.B.; Sulaiman, Z.; Usman, B.; Ibrahim, M.A. Effect of Henna Leaves on the Corrosion Inhibition of Tin in Acidic and Alkaline Media. World Journal of Applied Chemistry 2019, 4, 54-51, https://doi.org/10.11648/j.wjac.20190404.11.

31. Lavanya, D.K.; Priya, F.V.; Vijaya, D.P. Green Approach to Corrosion Inhibition of Mild Steel in Hydrochloric Acid by 1-[Morpholin-4-yl(thiophen-2-yl)methyl]thiourea. J Fail. Anal. and Preven. 2020, 20, 494-502, https://doi.org/10.1007/s11668-020-00850-9.

32. Mall, I.D.; Srivastava, V.C.; Agrwal, N.K.; Mishra, I.M. Adsorptive removal of malachite green dye from aqueous solution by bagasse fly ash and activated carbon-kinetic study and equilibrium isotherm analyses. Colloids Surf A: Physicochem. Eng. Aspects. 2005, 264, 17-28, https://doi.org/10.1016/j.colsurfa.2005.03.027.

33. Gaetano, P.; Katarzyna, B.; Edyta, P.; Jacek, B. Guar Gum as an Eco-Friendly Corrosion Inhibitor for Pure Aluminium in 1-M HCl Solution. Materials 2019, 12, https://doi.org/10.3390/ma12162620.

34. Fouda, A.S.; Zaki, E.G.; Khalifa, M.M.A. Some New Nonionic Surfactants Based on Propane Tricarboxylic Acid as Corrosion Inhibitors for Low Carbon Steel in Hydrochloric Acid Solutions. Journal of Bio- and Tribo-Corrosion 2019, 5, https://doi.org/10.1007/s40735-019-0223-y.

35. Habibiyan, A.; Ramezanzadeh, B.; Mahdavian, M.; Kasaeian, M. Facile size and chemistry-controlled synthesis of mussel-inspired bio-polymers based on Polydopamine Nanospheres: Application as eco-friendly corrosion inhibitors for mild steel against aqueous acidic solution. Journal of Molecular Liquids 2020, 298, https://doi.org/10.1016/j.molliq.2019.111974.

36. Xometi, O.O.; Likhanova, N.V.; Anguilar, M.A.D.; Arce, E.; Dorantes, H.; Lozada, P.A. Synthesis and corrosion inhibition of $\alpha$-amino acids alkylamides for mild steel in acidic environment. Mater. Chem. Phys. 2008, 110, 344-351, https://doi.org/10.1016/j.matchemphys.2008.02.010.

37. Motawea, M. M.; El-Hossiany, A.; Fouda, A.S. Corrosion Control of Copper in Nitric Acid Solution using Chenopodium Extract. Int. J. Electrochem. Sci. 2019, 14, 1372-1387, https://doi.org/10.20964/2019.02.29.

38. Li, W. Electrochemical and Computational Studies of Proline and Captopril as Corrosion Inhibitors on Carbon Steel in a Phase Change Material Solution. International Journal of Electrochemical Science 2020, 722-739, https://doi.org/10.20964/2020.01.63.

39. Fouda, A.S.; Badawy, A.A. Adsorption and corrosion inhibition of $\mathrm{Cu}$ in nitric acid by expired simvastatin drug, Protection of metals and physical chemistry surfaces. Protection of Metals and Physical Chemistry of Surfaces 2019, 55, 572-582, https://doi.org/10.1134/S2070205119030146.

40. Olasunkanmi, L.O.; Kabanda, M.M.; Ebenso, E.E. Quinoxaline derivatives as corrosion inhibitors for mild steel in hydrochloric acid medium: electrochemical and quantum chemical studies. Physica 2016, E 76, 109126, https://doi.org/10.1016/j.physe.2015.10.005.

41. Abdel Rehim, S.S; Hazzazi, O. A.; Amin, M.A.; Khaled, K.F. On the corrosion inhibition of low CS in concentrated sulphuric acid solutions. Part I: Chemical and electrochemical (AC and DC) studies. Corros. Sci. 2008, 50, 2258-2271, https://doi.org/10.1016/j.corsci.2008.06.005.

42. Fouda, A.S.; Abdel Haleem, E. Berry Leaves Extract as Green Effective Corrosion Inhibitor for Cu in Nitric Acid Solutions. Surface Engineering and Applied Electrochemistry 2018, 54, 498-507, https://doi.org/10.3103/S1068375518050034. 
43. Bosch, R.W.; Hubrecht, J.; Bogaerts, W.F.; Syrett, B.C. Electrochemical Frequency Modulation: A New Electrochemical Technique for Online Corrosion Monitoring. Corrosion 2001, 57, 60-70, https://doi.org/10.5006/1.3290331.

44. Abd El-Maksoud, S.A.; Fouda, A.S. Some pyridine derivatives as corrosion inhibitors for CS in acidic medium. Mater. Chem. Phys. 2005, 93, 84-90, https://doi.org/10.1016/j.matchemphys.2005.02.020.

45. Fouda, A.S.; Killa, H.M.; Farouk, A.; Salem, A.M. Calicotome Extract as a Friendly Corrosion Inhibitor for Carbon Steel in Polluted NaClSolution: Chemical and Electrochemical Studies. Egyptian Journal of Chemistry 2019, 62, 1879-1894, https://doi.org/10.21608/EJCHEM.2019.7656.1649.

46. El-Katori, E.E.; Fouda, A.S.; Mohamed R.R. The synergistic impact of the aqueous Valerian extract and Zn ions for the correction protection of mild steel in acidic environment. Z. Phys. Chem. 2019, In press https://doi.org/10.1515/zpch-2019-1377.

47. Fouda, A.S.; Abd El-Maksoud, S.A.; El-Hossiany, A.; Ibrahim, A. Evolution of the Corrosion-inhibiting Efficiency of Novel Hydrazine Derivatives against Corrosion of Stainless Steel 201 in Acidic Medium. Int. J. Electrochem. Sci. 2019, 14, 6045-6064, https://doi.org/10.20964/2019.07.65.

48. Soltani, N.; Tavakkoli, N.; Attaran, A.; Karimi, B.; Khayatkashani, M. Inhibitory effect of Pistacia khinjuk aerial part extract for carbon steel corrosion in sulfuric acid and hydrochloric acid solutions. Chemical Papers 2020, 74, 1799-1815, https://doi.org/10.1007/s11696-019-01026-y.

49. Hao, Y.; Sani, L.A.; Ge, T.; Fang, Q. The synergistic inhibition behaviour of tannic acid and iodide ions on mild steel in $\mathrm{H}_{2} \mathrm{SO}_{4}$ solutions. Corros. Sci. 2017, 123, 158-169, https://doi.org/10.1016/j.corsci.2017.05.001.

50. Fouda, A.S.; Abd El-Maksoud, S.A.; El-Hossiany, A.; Ibrahim, A. Effectiveness of Some Organic Compounds as Corrosion Inhibitors for Stainless Steel 201 in $1 \mathrm{M} \mathrm{HCl}$ : Experimental and Theoretical Studies. Int. J. Electrochem. Sci. 2018, 13, 9826-9846, https://doi.org/10.20964/2018.10.36.

51. Gökçe, H.; Bahçeli, S. A study on quantum chemical calculations of 3-, 4-nitrobenzaldehyde oximes. Spectrochim. Acta A. 2011, 79, 1783-1793, https://doi.org/10.1016/j.saa.2011.05.057.

52. Arivazhagan, M.; Subhasini, V.P. Quantum chemical studies on structure of 2-amino-5-nitropyrimidine. Spectrochim. Acta. 2012, 91, 402-410, https://doi.org/10.1016/j.saa.2012.02.018.

53. Kiyooka, S.; Kaneno, D.; Fujiyama, R. 'Parr's index to describe both electrophilicity and nucleophilicity. Tetrahedron Lett. 2013, 54, 339-342, https://doi.org/10.1016/j.tetlet.2012.11.039.

54. Fouda, A.S.; Rashwan, S.; El-Hossiany, A.; El-Morsy, F.E. Corrosion Inhibition of Zinc in Hydrochloric Acid Solution using some organic compounds as Eco-friendly Inhibitors. JCBPS. 2019, 9, 001-024, https://doi.org/10.24214/jcbps.A.9.1.00124.

55. Olasunkanmi, L.O.; Ebenso, E.E. Experimental and computational studies on propanone derivatives of quinoxalin-6-yl-4,5-dihydropyrazole as inhibitors of mild steel corrosion in hydrochloric acid. Journal of Colloid and Interface Science 2020, 561, 104-116, https://doi.org/10.1016/j.jcis.2019.11.097.

56. Saha, S.K.; Dutta, A.; Ghosh, P.; Sukul, D.; Banerjee, P. Novel Schiff-base molecules as efficient corrosion inhibitors for mild steel surface in $1 \mathrm{M} \mathrm{HCl}$ medium: experimental and theoretical approach. Phys. Chem. Chem. Phys. 2016, 18, 17898-911, https://doi.org/10.1039/C6CP01993E.

57. Saha, S.K.; Murmu, M.; Murmu, N.C.; Banerjee, P. Evaluating electronic structure of quinazolinone and pyrimidinone molecules for its corrosion inhibition effectiveness on target specific mild steel in the acidic medium: A combined DFT and MD simulation study. Journal of Molecular Liquids 2016, 224, 629-638, https://doi.org/10.1016/j.molliq.2016.09.110.

58. Fouda, A.S.; Abd El-Maksoud, S.A.; El-Hossiany, A.; Ibrahim, A. Corrosion Protection of Stainless Steel 201 in Acidic Media using Novel Hydrazine Derivatives as Corrosion Inhibitors. Int. J. Electrochem. Sci. 2019, 14, 2187-2207, https://doi.org/10.20964/2019.03.15.

59. Ardakani, E.K.; Kowsari, E.; Ehsani, A. Imidazolium-derived polymeric ionic liquid as a green inhibitor for corrosion inhibition of mild steel in $1.0 \mathrm{M} \mathrm{HCl}$ : Experimental and computational study. Colloids and Surfaces A: Physicochemical and Engineering Aspects 2020, 564, https://doi.org/10.1016/j.colsurfa.2019.124195. 